\title{
Fatores de Risco no Contexto de Adolescentes Envolvidos no Tráfico de
}

\author{
Drogas \\ Alex Sandro Gomes Pessoa* \\ Universidade Federal de São Carlos - UFSCar, São Carlos, SP, Brasil \\ ORCID: https://orcid.org/0000-0002-9271-8575 \\ Renata Maria Coimbra** \\ Universidade Estadual Paulista Júlio de Mesquita Filho - UNESP, Presidente Prudente, SP, Brasil \\ ORCID: https://orcid.org/0000-0003-2105-7260
}

\begin{abstract}
RESUMO
O objetivo deste artigo foi verificar os fatores de risco presentes no contexto de adolescentes com histórico de envolvimento no tráfico de drogas. Trata-se de um estudo de natureza qualitativa, exploratório-descritivo e com recorte transversal. Foram realizadas entrevistas semiestruturadas com 8 adolescentes que apresentavam envolvimento intenso no tráfico de drogas. As questões foram estruturadas levando em considerações diferentes dimensões da vida dos adolescentes, incluindo fatores de risco, bem como sobre a trajetória de envolvimento no tráfico de drogas. Os dados obtidos na investigação sugerem que os fatores de risco na vida dos adolescentes possuem três dimensões temporais: antes, durante e após o envolvimento no tráfico de drogas. Os resultados apontaram que o envolvimento no tráfico de drogas consolida um conjunto de variáveis que se mostram prejudiciais ao desenvolvimento dos adolescentes. Além das repercussões sociais debatidas neste manuscrito, materializados a partir do estigma que recebem, passam a depender financeiramente (seja para atividades de lazer, consumo ou auxílio às famílias) e psicologicamente (para manter o status social adquirido e até mesmo consumir as substâncias psicoativas) do tráfico de drogas.
\end{abstract}

Palavras-chave: adolescência, tráfico de drogas, fatores de risco, psicologia.

\section{Factors within the Context of Adolescents Involved in Drug Trafficking}

\begin{abstract}
This article aimed to evaluate the risk factors present in the context of adolescents with the history of involvement in drug trafficking. The fieldwork was qualitative in nature, exploratory and cross-cut. Semi-structured interviews were conducted with 8 adolescents with an intense involvement in drug trafficking. Questions were based on different dimensions of adolescents' lives, including risk factors, as well as the trajectory of involvement in drug trafficking. Data suggest that risk factors in adolescents' lives have three dimensions: before, during, and after involvement in drug trafficking. Findings showed that the involvement drug trafficking consolidates a set of variables that represents damage to the psychosocial
\end{abstract}


development of adolescents. In addition to the social repercussions discussed in this manuscript, illustrated by the stigma they receive, they depend financially (whether for leisure activities, consumption or family support) and psychologically (to maintain acquired social status and even consume psychoactive substances) drug trafficking.

Keywords: adolescence, drug trafficking, risk factors, psychology.

\section{Factores de Riesgo para los Adolescentes Involucrados en el Tráfico de}

\section{Drogas}

\section{RESUMEN}

Este artículo tuvo por objetivo evaluar los factores de riesgo presentes en el contexto de adolescentes involucrados en el tráfico de drogas. Es un estudio de naturaleza cualitativa, exploratorio-descriptivo y con recorte transversal. Se realizaron entrevistas semiestructuradas con 8 adolescentes que tenían una participación más intensa en las actividades ilícitas. Las cuestiones fueron estructuradas llevando en cuenta diferentes dimensiones de la vida de los adolescentes, incluyendo factores de riesgo, así como sobre la trayectoria de implicación en el tráfico de drogas. Los datos obtenidos en la investigación sugieren que los factores de riesgo en la vida de los adolescentes tienen tres dimensiones temporales: antes, durante y después de la participación en el tráfico de drogas. Los resultados mostraron que la participación en el tráfico de drogas consolida un conjunto de variables que son perjudiciales para el desarrollo de los adolescentes. Además de las repercusiones sociales discutidas en este manuscrito, materializadas a partir del estigma que reciben, dependen financieramente (ya sea para actividades de ocio, consumo o apoyo familiar) y psicológicamente (para mantener el status social adquirido e incluso consumir las sustancias psicoactivas) del narcotráfico.

Palabras-clave: adolescencia, tráfico de drogas, factores de riesgo, psicología.

O envolvimento de adolescentes em atos infracionais, especialmente o roubo e o tráfico de drogas, tem sido um tema de discussões no campo político, jurídico e acadêmico. Os marcos legais promulgados nas últimas décadas, como o Estatuto da Criança e do Adolescente (Lei n. 8069, 1990), o Sistema Nacional de Atendimento Socioeducativo (Lei n. 12.594, 2012) e as referências técnicas divulgadas pelo Conselho Federa de Psicologia (Conselho Federal de Psicologia, 2012a; 2012b), convocam os profissionais da psicologia a se engajarem em atividades formativas consistentes para atender esta demanda. Considera-se, desse modo, que a psicologia tem um papel fundamental na consolidação de modelos investigativos voltados à compreensão dos fatores de risco que expõem adolescentes aos atos infracionais. 
Sabe-se que o envolvimento do segmento infanto-juvenil no tráfico de drogas não é um fenômeno recente no Brasil (Vicentin \& Rosa, 2010). Ainda que de forma tímida, a psicologia, nos últimos anos, passou a se interessar pela compreensão dos fatores (sociais, psicológicos e relacionais) que explicariam o envolvimento de adolescentes em atos infracionais. Isso deu origem a modelos explicativos com bases epistemológicas distintas, nem sempre dialógicas. Neste artigo, considera-se que o recrutamento dos adolescentes no tráfico de drogas está intimamente ligado a questões de ordem econômica e estrutural que repercutem na constituição subjetiva dos adolescentes e tornam essa atividade atrativa para esse segmento (Paiva, Souza, \& Rodrigues, 2014).

A realidade da desigualdade social, fortemente evidenciada no Brasil, traz implicações profundas no desenvolvimento psicológico de grupos marginalizados, especialmente no caso de adolescentes e jovens que são arremessados nesta lógica perversa (Paiva, Souza, \& Rodrigues, 2014). Isso quer dizer que em realidades marcadas por privação de direitos e escassez de recursos que garantam o desenvolvimento das estruturas mentais, o psiquismo pode não se desenvolver em sua máxima potência (Mondini, 2011). Nestes casos, pode-se afirmar que esses grupos estão expostos a indicadores de risco, pois, em virtude da lógica do capital, são cerceados das possibilidades da apropriação cultural e o desenvolvimento das funções psicológicas superiores desses grupos são inibidas (Sawaia, 2014). Dessa maneira, entende-se que os profissionais da psicologia devem reconhecer que o envolvimento de adolescentes no tráfico está associado à presença de fatores de risco presentes nos contextos de desenvolvimento desse grupo (Pessoa, Coimbra, Koller, \& Ungar, 2018).

Fatores de risco podem ser definidos como variáveis que, quando presentes na vida de uma pessoa, da família, de determinadas comunidades ou culturas, impactam negativamente no percurso desenvolvimental dos envolvidos, pois impedem o desenvolvimento psicológico e social e expõem as pessoas a condições de subalternidade (Zappe \& Dell'Aglio, 2016; Morais, Raffaelli, \& Koller, 2012). Os fatores de risco não aparecem de forma espontânea no contexto de adolescentes com histórico de envolvimento no tráfico de drogas. Ao contrário, são expressões de um modelo de organização social marcado por profundas injustiças sociais e privação dos direitos fundamentais (Gomes \& Colaço, 2016).

A partir do reconhecimento da realidade de privação de direitos e da desigualdade de oportunidades, os profissionais da psicologia devem avaliar quais as variáveis que podem se constituir como fatores de risco que expõe os adolescentes ao tráfico de drogas. A hipótese central, como já apresentado, é que o recrutamento de adolescentes no comércio de substâncias psicoativas não é natural, despregado da realidade objetiva e material. 
Compreende-se que o contexto de precariedade e privação de diretos de famílias, especialmente àquelas desfavorecidas socioeconomicamente, coloca adolescentes em situação de vulnerabilidade e aumenta os riscos de engajamento em atividades ilícitas, como o tráfico de drogas. Assim, com base nessas prerrogativas, o objetivo deste artigo foi verificar os fatores de risco presentes no contexto de adolescentes com histórico de envolvimento no tráfico de drogas.

\section{Método}

\section{Participantes}

O trabalho de campo possibilitou a estruturação de um estudo qualitativo, exploratório descritivo e com recorte transversal. A pesquisa foi realizada com adolescentes que apresentavam um histórico de envolvimento no tráfico de drogas. O recrutamento dos participantes ocorreu junto um Cento de Referência Especializada em Assistência Social $(n=$ 21) e em três instituições de semiliberdade $(n=27)$, totalizando, na primeira etapa da investigação, 48 participantes provenientes de três cidades distintas. Todos os municípios eram de médio porte e se localizam no interior do estado de São Paulo. Os critérios de inclusão foram: (1) ter sido encaminhado à instituição por vinculação ao tráfico; (2) apresentar alto score na seção do instrumento que trazia elementos de valorização do tráfico de drogas (aferido através da técnica de análise discriminante); (3) por fìm, a concordância dos profissionais que atendiam os adolescentes quanto à valorização do tráfico (foi solicitado aos profissionais da equipe técnica que levassem em consideração discursos positivos em relação ao tráfico que apareceram espontaneamente durante os atendimentos).

\section{Instrumentos}

Para o desenvolvimento de um estudo qualitativo, que culminou na elaboração deste artigo, interessava aos pesquisadores recrutar os adolescentes com envolvimento mais crônico (ou mais agravado) com o tráfico de drogas, pois entendia-se que os mesmos poderiam trazer dados mais aprofundados sobre os fatores de risco. Para tanto, foi utilizado, na primeira etapa da investigação com os 48 adolescentes, um instrumento denominado Child and Youth Resilience Measure - CYRM. Este material foi criado a partir de uma pesquisa intercultural realizada com 1451 adolescentes, que residiam em 14 comunidades de 11 países diferentes 
(Ungar, Clark, Kwong, Camaron, \& Makhnach, 2005; Ungar et al., 2007), sendo considerado um instrumento para avaliar indicadores de resiliência. $\mathrm{O}$ instrumento foi traduzido pela segunda autora deste artigo, tendo como suporte o manual de usuário e sob a supervisão direta de Michael Ungar e Linda Liebenberg, idealizadores do material. O instrumento é composto por 28 itens, estruturados no modelo da escala likert e solicita que os participantes assinalem apenas um item de acordo com seus níveis de concordância nas afirmações. O instrumento é composto por duas seções, sendo que a primeira objetiva identificar processos de resiliência a partir de dimensões individuais, relacionais, contextuais e culturais. A escolha por esta ferramenta se deu em virtude da sensibilidade de seus idealizadores para os aspectos contextuais que promovem resiliência em diferentes culturas e nacionalidades. Além disso, o instrumento possui uma seção na qual os pesquisadores podem elaborar itens que estejam condizentes com os objetivos de cada pesquisa e que sejam relevantes culturalmente. Alinhado com o objetivo deste artigo, esta seção foi composta por itens relacionados ao tráfico de drogas envolvendo adolescentes e percepções valorativas do tráfico de drogas (Ex.: "Vender droga deveria ser visto como uma forma digna de ganhar dinheiro"). Como o material estava organizado no modelo de escala likert, procedeu-se com uma técnica estatística de agrupamento (técnica de cluster) para constituir um grupo homogêneo em relação às respostas fornecidas a estes itens. Dessa forma, participaram das entrevistas oito adolescentes do sexo masculino, com idade média de 16,8 anos $(D P=1,79)$, que apresentaram, através do instrumento empregado, mais valorização do tráfico de drogas (ver um detalhamento em Pessoa, 2015). Estes adolescentes foram entrevistados individualmente a partir de um roteiro de entrevista semiestruturado previamente desenvolvido pelos pesquisadores. As questões versavam sobre os seguintes aspectos: família; escolarização; projetos sociais e serviços de atendimento; sentidos pessoais atribuídos ao engajamento no tráfico de drogas; justiça social; projetos futuros.

\section{Procedimentos, análise de dados e confiabilidade}

A partir de apontamentos da literatura, foi elaborado um roteiro de questões semiestruturado que versava sobre diferentes dimensões da vida dos adolescentes (incluindo fatores de risco e proteção), bem como do histórico de envolvimento no tráfico de drogas. Os participantes tinham o direito de ler as questões contidas no roteiro antes do início da técnica, negar responder parte delas ou até mesmo não dar continuidade à pesquisa. Com a maioria 
dos participantes, as entrevistas foram realizadas em duas sessões, sendo que todo o conteúdo foi gravado e, posteriormente, transcrito na íntegra.

Os dados foram submetidos à análise de conteúdo, inspirados na proposta de Bardin (2011) e permitiram a criação de categoriais explicativas sobre o fenômeno investigado fatores de risco presentes no contexto de vida de adolescentes envolvidos no tráfico de drogas. Para aumentar o grau de confiabilidade das categorias, todo o material foi analisando separadamente pelos autores deste artigo, sendo as discrepâncias resolvidas por consenso, sempre tomando por base as teorias que fundamentaram o trabalho.

\section{Questões éticas}

O estudo tomou como referência as normativas estabelecidas pelo Conselho Nacional de Saúde através da portaria 466/2012e 510/2016. O projeto de pesquisa foi aprovado pelo Comitê de Ética em pesquisa da Faculdade de Ciência e Tecnologia da Universidade Estadual Paulista - Campus de Presidente Prudente (CAEE 26468714.0.0000.5402).

\section{Resultados}

A análise de conteúdo revelou três categorias centrais: (1) Ritos de iniciação e intergeracionalidade do tráfico de drogas; (2) Rompimentos de vínculos familiares e institucionais; (3) Repercussões sociais e subjetivas nos adolescentes que se envolveram no tráfico de drogas. Os dados obtidos na investigação sugerem que os fatores de risco na vida dos adolescentes possuem três dimensões temporais: antes, durante e após o envolvimento no tráfico de drogas. A Tabela 1 sumariza as categorias encontradas e as relaciona com as dimensões temporais dos fatores de risco para os adolescentes que participaram do estudo. 
Tabela 1

Sintese das Categorias

\begin{tabular}{llc}
\hline Categorias & \multicolumn{1}{c}{ Descrição } & $\begin{array}{c}\text { Dimensão temporal do fator } \\
\text { de risco }\end{array}$ \\
\hline $\begin{array}{l}\text { Ritos de iniciação e } \\
\text { intergeracionalidade } \\
\text { do tráfico de drogas }\end{array}$ & $\begin{array}{l}\text { Início do envolvimento dos } \\
\text { adolescentes na comercialização das } \\
\text { drogas, bem como o processo } \\
\text { intergeracional no engajamento dessa } \\
\text { atividade }\end{array}$ & $\begin{array}{c}\text { Antes do engajamento no } \\
\text { tráfico de drogas }\end{array}$ \\
$\begin{array}{l}\text { O envolvimento dos adolescentes no } \\
\text { Rompimentos de } \\
\text { vínculos familiares e } \\
\text { institucionais é decorrente ou acontece } \\
\text { paralelamente ao rompimento ou } \\
\text { fragilização de vínculos familiares e }\end{array}$ & $\begin{array}{c}\text { Durantes o período de } \\
\text { comercialização de drogas }\end{array}$ \\
$\begin{array}{l}\text { Repercussões sociais } \\
\text { institucionais subjetivas nos }\end{array}$ & $\begin{array}{c}\text { Implicações sociais e psicológicas } \\
\text { para os adolescentes após o }\end{array}$ & $\begin{array}{c}\text { Após o rompimento com a } \\
\text { venda de drogas, sobretudo } \\
\text { a partir da aplicação de }\end{array}$ \\
$\begin{array}{l}\text { adolescentes que se } \\
\text { envolveram }\end{array}$ no \\
tráfico de drogas
\end{tabular}

Ritos de iniciação e intergeracionalidade do tráfico de drogas

Nessa categoria foram considerados excertos que reportavam o início do envolvimento dos adolescentes na comercialização das drogas, bem como o processo intergeracional no engajamento dessa atividade. Estes temas foram centrais para compreender como se deu a inserção dos adolescentes no tráfico e os ciclos que se perpetuam nas famílias, impossibilitando o rompimento dos fatores de risco.

Os amigos da escola, do bairro e familiares próximos foram apontados como os principais responsáveis pela vinculação inicial ao tráfico. Constatou-se, desse modo, que o recrutamento dos adolescentes nessas atividades não ocorre por intermédio de ações diretas de facções criminosas. Além disso, os participantes relataram que o início da comercialização ocorreu após as primeiras experiências como usuários das substâncias psicoativas, principalmente a maconha. Na maioria dos casos, essas experiências ocorreram no final da infância ou início da adolescência. As entrevistas revelaram regularidade no envolvimento no tráfico de drogas para os adolescentes que participaram do estudo. Trata-se de um processo ritualístico, iniciado com a aproximação de alguém que já está no tráfico, seguido pelas primeiras experiências como usuários (sobretudo da maconha), passando para a venda de pequenas porções e, progressivamente, ocorre a intensificação no comércio das substâncias psicoativas.

Também chamou atenção o fato dos participantes relatarem que familiares e pessoas que ocupam um espaço importante em suas vidas já estiveram envolvidos com o tráfico. Alguns membros das famílias, como tios e pais, foram assassinados e/ou presos pelo 
envolvimento com grupos criminosos, indicando que este fator de risco persiste entre diferentes gerações no mesmo núcleo familiar. Todavia, os adolescentes afirmaram que estas pessoas, em virtude de suas experiências danosas com o tráfico, os alertavam constantemente sobre os riscos dessa atividade e os aconselhavam a se afastarem de situações que os colocassem em risco. Os conteúdos evocados nas entrevistas e que embasaram esta categoria podem ser visualizados na Tabela 2 .

Tabela 2

Ritos de Iniciação e Intergeracionalidade do Tráfico de Drogas

$$
\text { Ritos de iniciação }
$$

Artur: Porque eu fui no embalo dos moleques. Comecei a andar com os moleques da escola, daí nós começamos a sair e eu já parei de andar com minha famillia, só andava com os moleques. Teve vez que eu voltava pra minha casa só pra pegar roupas, essas coisas, nem dormia. Eu dormia na outra casa que eu tinha.

Bernardo: No tráfico, foi mais na amizade assim. Minha irmã, antes dela casar, ela já era envolvida. Então eu era super apegado com minha irmâ e eu ia em todo lugar junto com ela. Aí eu conheci uns amigos dela que viraram meus amigos e foi quando eu comecei a entrar no tráfico [...] pra mim acho que foi pelo dinheiro, porque quando eu traficava eu ganhava muito.

Luciano: Minha mãe é separada do meu pai. Meu pai mora numa vila e minha mãe mora em outra. A vila que minha mãe mora é aquele tipo civilizada. A vila que meu pai mora é tipo uma favela e eu sempre fui pra casa do meu pai. Ali eu comecei a arrumar uns colegas e, os meus colegas que arrumei foram os mesmos que me envolveram nesse negócio.

Gustavo: Ah, vendo com os outros assim, um dinheiro, ai eu fui de embalo. Eu andava com os moleques que vendiam droga. Eu via eles com dinheiro sempre e quis me envolver também. Mais de embalo eu fui.

Thiago: Sou eu, meu outro irmão e uma irmã. Eu sou o mais velho. Eu que cuido deles agora. Sempre cuidei, porque minha irma foi morar com a tia dela quando minha mãe morreu. Ai meu irmâo ficou com meu pai. Mas pelo fato dela ser mulher e era pequeninha, ele mandou ela pra lá, pra não se envolver, não viver aquela vida que nós estávamos vivendo. Ai meu pai morreu depois de 3 anos, depois da minha mãe. Ai como eu já tinha vivido bastante tempo no crime, eu já sabia a noção. Eu comecei vender drogas, participar do crime, já timha envolvimento com as pessoas.

Pesquisador: $E$ depois que seu pai foi assassinado, pra onde você foi?

Thiago: Ai fiquei sozinho né. Fui vender droga. Com 11 anos morava com mulher já. Já era casado já, tinha biqueira, tinha casa.

\begin{tabular}{l} 
Intergeracionalidade do tráfico \\
\hline Pesquisador: E seu pai? \\
Bernardo: Meu pai eu não conheci, porque quando minha mãe estava grávida ele morreu \\
[...] mataram ele, deram tiro. Ele era envolvido no tráfico. \\
Marcelo: Foi surpresa, eles não sabiam enem desconfiavam [sobre o envolvimento no tráfico]. \\
Pesquisador: E o que te falaram? \\
Marcelo: Minha mãe falou que era pra eu parar, que não virava, que eu tinha exemplo já na \\
familia. \\
Pesquisador: Que exemplo? \\
Marcelo: Meu pai está lá, meu pai está preso. Meu tio tinha acabado de sair. Ela falou que era pra \\
eu pensar o que eu queria da minha vida. \\
Pesquisador: Como vocé aprendeu? \\
Thiago: Querendo ou não, eu aprendi com meu pai e minha mãe, sem eles quererem me ensinar. Eu \\
escondido, eu aprendí. Quando eles iam picar, eu sempre ficava olhando assim. Eles trancavam a \\
gente lá no quarto pra picar droga, mas mesmo assim eu sabia. Ia lá depois e via as sacolinhas \\
cortadas e já comę̧a a montar o quebra cabeça. Fui vendo... meu pai ia esconder a droga, ia \\
vender lá longe, porque tīnha medo das policias pegarem ele. Então eu já pensava que quando eu \\
fosse vender... "Vou levar a droga lá em baixo, longe".
\end{tabular}




\section{Rompimentos de vínculos familiares e institucionais}

Os dados compilados e apresentados na Tabela 3 permitiram compreender que o envolvimento dos adolescentes no tráfico é decorrente ou acontece paralelamente ao rompimento ou fragilização de vínculos familiares e institucionais. Os resultados apontaram problemas nos relacionamentos interpessoais estabelecidos com a família, sobretudo a figura paterna e, também, rompimentos bruscos com determinadas instituições, em especial a escola e a polícia. As entrevistas revelaram que as relações com a figura paterna são, na maioria dos casos, estremecidas e conturbadas, com episódios de violências constantes e histórico de dependência química dos genitores. Os adolescentes descreveram situações vexatórias que foram expostos, bem como a dificuldade que encontravam em dialogar com os pais. As mães também foram mencionadas, mas, nestes casos, os relatos eram acompanhados por argumentos que justificariam as ações, ainda que as condutas se configurassem como formas de violência.

Os excertos que se relacionam com as experiências escolares dos adolescentes, antes e durante o envolvimento no tráfico, também foram analisados. Não são todos os entrevistados que valorizaram as possibilidades e oportunidades que os processos de escolarização podem trazer, mas alguns reconhecem que dificilmente as pessoas são bem-sucedidas se não adquirirem uma formação educacional satisfatória. Narraram poucas experiências positivas no contexto escolar, limitando-se a lembranças pontuais com alguns professores, funcionários e amigos, mas raramente com o próprio processo de aprendizagem.

Os participantes mostraram que se sentiam desconfortáveis no contexto escolar e, de certa forma, inadaptados às rotinas propostas. Por isso, a escola foi indicada como uma instituição positiva para o futuro, mas com poucos referenciais positivos relacionados ao presente, capazes de gerar o sentimento de pertencimento à instituição. Ao contrário, quando tentavam retornar à escola após o período de internação, sentiam-se estigmatizados e perseguidos pela equipe pedagógica, que, na percepção dos adolescentes, os responsabilizavam por todas as ocorrências da escola relacionadas à indisciplina ou depredação do patrimônio (estes dados se associam com os achados da próxima categoria).

A partir de toda essa conjuntura, os adolescentes falaram de suas dificuldades de permanecerem na escola, especialmente após o envolvimento no tráfico. Em quase todos os casos, o abandono escolar é concomitante a este momento. Alguns dos participantes afirmaram que, no início, conseguiam conciliar o tráfico e a escola; mas, com o aumento das demandas, necessitam se ausentar cada vez mais da sala de aula. Assim como ocorreu com os 
familiares, os funcionários da escola não notaram o início do envolvimento dos adolescentes no tráfico. Alguns participantes relataram que os funcionários da escola observavam a ausência constante dos adolescentes, mas não faziam relações com o que estava ocorrendo.

Os participantes revelaram, ainda, manter uma relação ainda mais conturbada com a polícia e expressaram, veementemente, baixos níveis de confiança nesta instituição. Contaram sobre situações abusivas e desrespeitosas ocorridas antes e durante o período que comercializavam as drogas, bem como o quanto se sentem perseguidos após cumprirem a medida socioeducativa. As batidas policiais, conhecida pelos participantes como enquadres, são frequentes e a estratégia mais utilizada para evitar que isso aconteça, segundo os adolescentes, é não andar em grupos na comunidade ou com pessoas que possam levantar suspeita de envolvimento em atividades ilícitas.

Os conflitos estabelecidos com a polícia envolvem agressões físicas, situações de humilhação e até mesmo formas de tortura. Em todas as entrevistas aparecem informações sobre morte de pessoas que trocaram tiros com a polícia por envolvimento no tráfico e que eram próximas aos adolescentes (amigos e parentes). Este cenário implica na desvalorização do trabalho da polícia, no rebaixamento dos níveis de confiança e no rompimento de relações sustentadas pelo respeito e credibilidade. Assim, tanto o início do envolvimento do tráfico quanto à permanência dos adolescentes nesta atividade estão meticulosamente articulados com o rompimento de vínculos institucionais. Os dados empíricos desta investigação, apresentados na Tabela 3, evidenciam como isso ocorre na família, na escola e com as intuições de segurança pública, mas certamente caberia uma investigação mais aprofundada sobre outros contextos desenvolvimentais. 
Tabela 3

Rompimentos de Vinculos Familiares e Institucionais

\section{Cuidados paternos precánios}

Luciano: Com meu pai eu comecei brigar assim, depois que ele ia pro bar e enchia a cara de pinga, cerveja. Chegava em casa revoltado e batia na minha mãe. Ai eu já brigava com ele também, já ficava cada um no seu canto, tinha vez que ele ia dormir pra fora, ficava uns més, não voltava mais. Pegava faca e vinha pra cima da familia inteira.

Thiago: Não tinha pra onde ir, o que comer. A única vida que eu tinha pra seguir era aquela. Se não eu ia viver onde? Sem paí, sem mãe, sem ninguém. Porque meus parentes são de XX (cidade) e nós viemos de lá fugidos: eu, minha mãe e meu irmão. Porque eu tinha um pai... porque esse que morreu não era meu pai de sangue... aí eu tinha um pai lá e ele judiava de nós. Usava crack. Nós éramos pequenininhos e ele queimava a gente com bituca de cigarro, torturava. Ai minha mãe pegou uns trens louco da vida, porque ela ia visitar ele na cadeia antes.

\begin{tabular}{|c|}
\hline \\
\hline $\begin{array}{l}\text { Pesquisador: E como era a sua relação com os seus professores? } \\
\text { Bernardo: Eu não tratava bem eles [...] eu não sei direito, mas eu acho que era a revolta de } \\
\text { ter que ir pra escola, porque ninguém gosta, eu não sei explicar direito. Mas acho que era } \\
\text { mais a revolta de estar lá, ter que estudar. }\end{array}$ \\
\hline $\begin{array}{l}\text { Gustavo: Eu ia só de vez em quando [à escola]. } \\
\text { Pesquisador: Sempre foi assim? } \\
\text { Gustavo: Não, antes eu ia todo dia, não faltava. Depois que eu comecei a vender [drogas] eu } \\
\text { ia só de vez em quando. Ai eu dava um jeito de não ir. Eu fiquei } 4 \text { meses sem ir pra escola. } \\
\text { Sem ir nem um dia [...] eles ligavam, só que eu enganava minha mãe, falava que eles estavam } \\
\text { mentindo pra ela. At ela ficava meio assim, ai não sei. } \\
\text { Pesquisador: Você gosta de ir pra escola? } \\
\text { Marcelo: Não. } \\
\text { Pesquisador: O que você não gosta na escola? } \\
\text { Marcelo: Não gosto de nada na escola [...]Eu vou, tenho que ir, marcar presença. Eu fico lá } \\
\text { conversando, escutando música no celular. } \\
\text { Pesquisador: Você acha que os estudos são importantes na sua vida? } \\
\text { Marcelo: Eu acho que não [...] com estudo ou sem estudo acho que tanto faz. }\end{array}$ \\
\hline \\
\hline $\begin{array}{l}\text { leu amigos? } \\
\text { ns } 5 \text {. Tem um recente agora que o policial deu dois tiros nele. Tem } \\
\text { olícia deu tiro nele e ele morreu. Era menor, tinha acabado de sair } \\
\text { na rua e morreu [...] Tinha um amigo meu, que estava na função } \\
\text { costurado. Ele foi roubar ai o policial deu } 21 \text { tiros nele e ele não } \\
\text { mo. } \\
\text { i na hora que eu estava subindo os policiais me paravam e batiam } \\
\text { ra e parei de ir pra escola. Estudava à tarde [...]Eles não gostavam } \\
\text { m que eu vendia, porque eram os mesmos policias. [...] Ai eu falei } \\
\text { ra escola pra apanhar". [...] Eles faziam eu assinar B. O que nem } \\
\text { m umas câmeras lá na escola ai falaram que foi eu e um outro } \\
\text { i fez a gente assinar esse B.O. } \\
\text { acha da policia, Luciano? } \\
\text { empre vou falar mal deles, mas pra turma perto da onde eu moro lá, } \\
\text { é senhor? Faz tudo de bom, protege a sociedade... mas pra mim }\end{array}$ \\
\hline
\end{tabular}




\section{Repercussões sociais e subjetivas nos adolescentes que se envolveram no tráfico de drogas}

Nesta categoria são apresentadas as implicações sociais e psicológicas para os adolescentes após o envolvimento no tráfico de drogas. Apesar do inegável aumento do poder de consumo, os resultados mostraram que os participantes têm prejuízos em diversas áreas de suas vidas. A obtenção de lucros requer cada vez mais investimentos, o que significa que os adolescentes precisam passar mais tempo comercializando as drogas. Progressivamente, em virtude da exposição nas suas comunidades e da medida de internação que receberam, passavam a se sentir rotulados em suas comunidades. Além disso, alguns entrevistados revelaram que uma parte das drogas servia para consumo próprio, repercutindo negativamente em outras esferas (como no ambiente escolar).

Unanimemente, os entrevistados alegaram que o tráfico de drogas permitiu o acesso a recursos e bens de consumo, como roupas de marcas, tênis, bonés de marca, entre outros. Citaram, ainda, as festas aos finais de semana, sempre acompanhas de episódios intensos do consumo de bebidas alcoólicas e drogas ilícitas. Nessas ocasiões, tinham o hábito de pagar a conta de outras pessoas, incluindo amigos próximos, mas também de pessoas sem vínculos afetivos e sociais significativos. Justificavam que usar roupas de marca e consumir na vida noturna geravam status e garantiam o reconhecimento do grupo. O tráfico de drogas também auxiliava, de acordo com os entrevistados, nas relações afetivo-sexuais. Revelaram que ser reconhecido como "traficante" em suas comunidades é algo que chama a atenção das mulheres (adolescentes do gênero feminino). Mas também é importante salientar que os participantes do estudo verbalizaram que o dinheiro obtido no tráfico possibilitava ajudar suas famílias com as contas mensais e na compra de mantimentos.

Todos os adolescentes reportaram o uso de diversas drogas, especialmente maconha, cocaína, cigarro e bebidas alcoólicas. Alguns afirmaram usar frequentemente as substâncias psicoativas, o que pode sugerir um quadro de dependência química. Outros parecem consumir moderadamente, mais associado ao uso recreativo em festas e aos finais de semana. Entretanto, foram encontrados prejuízos sociais em todos os casos e uma forte relação entre o uso de substâncias psicoativas e o abandono escolar. Os adolescentes, ao menos do ponto de vista discursivo, relatam a incompatibilidade entre o tráfico e o consumo de drogas, embora façam as duas coisas simultaneamente. É de conhecimento dos participantes, por exemplo, que o uso pode implicar em prejuízos financeiros que, por sua vez, pode se desdobrar em dívidas com traficantes e facções criminosas. 
Diversos relatos de práticas discriminatórias foram encontrados nas entrevistas com os participantes do estudo. Essas situações ocorreram após os adolescentes receberem uma medida socioeducativa e eram expressas através de preconceito racial, pelos lugares em que moravam, pela maneira que se vestiam e / ou se comportavam em determinados espaços sociais. Alguns deles falam sobre os estereótipos que carregam e como isso os identificava, seja na comunidade ou pela própria polícia. Os participantes informaram que as pessoas comentam com frequência sobre a relação deles com o tráfico, sobretudo depois que retornam do período de internação. Dessa maneira, afirmam que têm dificuldades para encontrar empregos ou mesmo de estabelecerem relações interpessoais, pois ao receberem uma medida ficam marcados e reconhecidos como pessoas ligadas ao crime.

Assim, como destacado na Tabela 4, o envolvimento no tráfico de drogas consolida um conjunto de variáveis que se mostram prejudiciais ao desenvolvimento dos adolescentes. Além das repercussões sociais debatidas neste manuscrito, materializados a partir do estigma que recebem, passam a depender financeiramente (seja para atividades de lazer, consumo ou auxílio às famílias) e psicologicamente (para manter o status social adquirido e até mesmo consumir as substâncias psicoativas) do tráfico de drogas. 
Tabela 4

Marcadores Sociais, Dependência Financeira e Psicológica

Poder de consumo

Pesquisador: Você acha que se você não estivesse preso...

Luciano: Estaria no tráfico [...] Por causa da ambição, senhor, $O$ dinheiro fala pra você. $O$ dinheiro hoje tá levando a gente a fazer maluquice.

Pesquisador: $O$ que vocé fazia com seu dinheiro?

Cléber: Tudo em baladinha. Em balada, marmita. Baile funk [...] eu gastava quinhentos, mil reais em uma noite. Nós pagávamos 50 do taxi, 50 pra ir, 50 pra voltar, que dava cem. At chegava lá pegava um litro de whisque, fora as outras coisas que nos pegávamos. Gastava mesmo [...]É dinheiro muito fácil. Você fala assim "Ah, vou gastar esse dinheiro que amanhã eu tenho mais". O bagulho vai que nem água.

Junior: Ah, voce faz dinheiro pra caramba, todo dia, acho que você ganha uns 600 reais por dia.

Pesquisador: $E$ com que as pessoas gastam?

Júnior: Ah, o que eu ganhava eu ia lá e gastava só com bebida, chamava mulher pra tomar, só tomava wisque, pagava as coisas pros outros... e roupa também, só roupa de marca, uns par de tênis.

Pesquisador: Que drogas você já usou?

Dependência química

Marcelo: Maconha, lance e bebida só. Pó não e nem crack.

Pesquisador: Maconha vocè fumava?

Marcelo: Fumava. Nem sei, mas era bastante. Era quase toda hora, acho que dava mais de 10. E final de semana era pior, porque tem piãozinho [...] Ai consome mais bebida, droga. $O$ que mais usa é isso.

Pesquisador: Como foram tuas experiências na escola?

Bernardo: Ah no começo eu me dava bem, mas depois que eu comecei a fumar maconha e ia pra escola, não dava muito bem não. Porque entrava na sala de aula já batia aquela revolta "Nossa, o que eu estou fazendo aqui?". Eu falava "Não, eu quero ir embora" e eles não deixavam. Eu pegava e saia, pulava o muro e ia embora.

\section{Preconceito e estigma}

Bernardo: Porque como eu saí, várias pessoas me olham com um olhar diferente. Já falam "Nossa, olha lá, ele saiu. Estava preso igual um presidiário, traficante, usuário. Então as pessoas olham vocé assim com um olhar diferente [...] nossa é isso que me dá mais raiva, que me dá cada vez mais vontade de entrar no tráfico, pra eu ver a cara daquela pessoa mudar... não só com medo e dó, mas pra ela sentir mais medo pra pessoa falar assim "Nossa, olha aquele moleque ali". Vai me olhar diferente, mais com respeito [...] é pra ganhar o respeito delas e não elas ficarem olhando pra mim e falando "Nossa, esse moleque é um expresidiário". Isso que me dá mais revolta.

Cléber: Depois que fui pra fundação, sei lá, só o povo da minha comunidade mesmo ficou meio pá. Sou de XX, é uma cidade pequena, lá todo mundo se conhece, deve ter uns $8 \mathrm{mil}$ habitantes... é pequena. Todo mundo ficou sabendo quando eu já fui preso.

Pesquisador: Voce já foi discriminado de alguma forma?

Thiago: Ah direto. Até agora, pelo jeito, pela minha fisionomia de ser, as pessoas pensam que sou bandido, pelo jeito que sou. Mas eu sempre fui assim, minha personalidade sempre foi essa. Mas tem gente que me olha que fala "Vixi, que cara de bandido". E eu não consigo esconder a pessoa que eu sou pra ninguém. Porque eu passei na Febem, pela tatuagem que eu tenho de um monte de palhaço com arma nas costas. $O$ palhaço é matador de policia. 


\section{Discussão}

O recrutamento dos adolescentes ao tráfico se deu por intermédio de pessoas próximas, especialmente amigos da escola ou que moravam perto de suas casas. Entretanto, em concordância com Ungar (2004), a "pressão dos pares" não é o elemento central na explicação do envolvimento de adolescentes em atividades ilícitas. As estruturais macrossociais e a ausência de ações governamentais adequadas produzem modos de sociabilidade alternativos para as populações infanto-juvenis. Nesta conjuntura, as atividades ilícitas despontam como práticas culturais que marcam determinados contextos comunitários e permeiam as relações entre pares.

Todos os jovens entrevistados eram pertencentes a camadas populares e relataram inúmeras dificuldades financeiras de suas famílias. O processo de exclusão e o impedimento da participação social efetiva, em termos de acesso a recursos materiais básicos, configura um fator impactante para o acometimento do ato infracional, especialmente no tráfico, que permite o acúmulo de capital financeiro de forma rápida (Cairus \& Conceição, 2010; Rocha, 2013). Também é importante salientar a complexidade das relações intrafamiliares, tais como compostas por muitos membros, expostas a situações de pobreza extrema e possuíam histórico de múltiplas formas de violências (Predebon \& Giongo, 2015; Pessoa, 2015). Todos estes fatores devem ser entendidos como variáveis relevantes, pois evitam formas de estigmatização e culpabilização exclusiva da família. Os dados relacionam-se com ciclos de exclusão que se perpetuam intergeracionalmente e que são difíceis de romper (Rodrigues \& Chalhub, 2014), formando, desse modo, um espiral que perpetua a exclusão e a necessidade da aderência a atividades ilícitas como forma de obtenção de recursos.

Os adolescentes que participaram do estudo eram provenientes de famílias que estavam expostas a diversos fatores de risco ao desenvolvimento de seus membros, não apenas de questões de ordem econômica e material, mas também em suas dinâmicas de funcionamento. Estudos já realizados com essa população evidenciam indicadores de risco cronificados no contexto intrafamiliar de adolescentes envolvidos no tráfico de drogas, como por exemplo, histórico de múltiplas violências, casos de dependência química, situação de extrema pobreza, e assim por diante (Predebon \& Giongo, 2015; Nardi \& Dell'Aglio, 2014). Isto reitera a necessidade de as famílias dos adolescentes com envolvimento no tráfico serem incluídas em diferentes políticas sociais, objetivando a emancipação e rompimento de práticas parentais tóxicas (Costa \& Goldani, 2015). 
A evasão escolar e a dificuldade de adaptação no contexto escolar também podem se configurar como fatores significativos para que haja envolvimento e reincidência no tráfico. Com base nas pesquisas de Silva e Salles (2011), Bazon, Silva e Ferrari (2013) e Padovani e Ristum (2013), aponta-se para a necessidade da implantação de ações educativas mais alinhadas com as expectativas de adolescentes com histórico no tráfico de drogas, enfatizando a participação efetiva desta população nos processos escolares. A pesquisa mostrou que o início do tráfico e a evasão escolar ocorrem quase que simultaneamente. As relações na instituição se mostram complexas, com relatos de desrespeito mútuo entre os adolescentes e profissionais (especialmente professores e diretores) e um histórico de violência alarmante. Os índices de reprovação também devem ser levados em consideração, pois estão relacionados com a evasão escolar, especialmente no caso dos adolescentes do tráfico, que acabam ocupando seu tempo com outras atividades (Pessoa \& Coimbra, 2016).

A falta de credibilidade da polícia, os discursos de ódio e o desejo de acerto de contas foram revelados pelo grupo entrevistado. Houve várias declarações de abuso de autoridade, situações de perseguição, violência física e psicológica, o que se assemelha ao estudo de Azevedo, Amorim e Alberto (2017). Esses indicadores estão em sintonia com os apontamentos de Marques e Rocha (2010), que explicam que "a maneira que os policiais lidam com os cidadãos pobres e marginalizados traz à tona uma característica comum a todas elas: o abuso do poder e do uso da agressão física como forma de eliminar um "inimigo"” (Marques \& Rocha, 2010, p.49). Na mesma direção, Coelho, Pessoa e Bottrell (2017) consideram que existe uma demarcação clara de territórios e das populações juvenis que, por serem suspeitas da polícia, recebem um tratamento hostil.

A pesquisa também revelou a possibilidade de os adolescentes adquirirem, através do tráfico, produtos de marca e de alto valor no mercado. Esse aspecto pareceu mais relevante do que superar a condição de pobreza que as famílias estavam expostas. Oliveira e Tomazetti (2012) apontam que adolescentes e jovens são arremessados numa lógica de consumo que os faz sempre querer novos produtos, sendo que esses objetos, por sua vez, "logram significativa incidência na subjetivação dos jovens contemporâneos" (p. 189). Contudo, a participação nessa lógica de consumo imposta pelo sistema capitalista produz modos de existências individualistas, que substitui o "ser" pelo "ter", promove disputas descabidas e estabelece padrões hedonistas (Guitart, 2011).

Grande parte dos lucros obtidos através do tráfico é destinada as festas aos finais de semana, sempre envolvendo usos abusivos de substâncias psicoativas, especialmente álcool, cigarro, maconha e cocaína. Esses dados coincidem com o material empírico coletado por 
Kessler (2010) e Rocha (2013), que problematizam, ainda, como os adolescentes com envolvimento no tráfico ou em outras atividades ilícitas se queixam da monotonia de suas cidades. A criação de espaços de lazer e o oferecimento de programas artísticos e culturais diversificados podem ser alternativas para que os adolescentes ampliem seu repertório de atividades sociais, que parecem muito restringidos à vida noturna e ao uso de entorpecentes (Pessoa, 2015).

As práticas discriminatórias são uma constante na vida dos adolescentes que praticaram o tráfico de drogas (Rocha, 2013). Mas não se trata apenas de situações que revelam preconceito em virtude do envolvimento do grupo em atividades consideradas ilícitas. Os participantes da pesquisa informaram que as marcas sociais que carregam, como as roupas que usam, o vocabulário que utilizam, a forma de andar e os lugares em que moram, são mal vistos, de forma geral, pelas pessoas. Crochik, Casco, Ceron e Catanzaro (2009) definem o preconceito como "uma expressão de atitudes hostis contra minorias e produto das relações entre as necessidades psíquicas e a ideologia" (p. 125). Os adolescentes do tráfico perturbam uma organização social idealizada pela burguesia e, de certa forma, apontam as mazelas e contradições sociais (Pessoa, Coimbra, Koller, \& Ungar, 2018); por isso, sofrem na pele, cotidianamente, com as imposições e brutalidade da não aceitação da diferença (Coelho, Pessoa, \& Bottrell, 2017).

O preconceito, o estigma e a intolerância com os adolescentes que participam do tráfico acentuam a desigualdade de oportunidades dessa população, uma vez que impedem a criação de um senso de pertencimento e inviabiliza a promoção de justiça social. A redução do estigma, articulado com programas interventivos, formação de educadores e profissionais da área da saúde, educação e assistência, podem auxiliar na construção de espaços de fortalecimento desse seguimento da população (Saewyc et al., 2013).

A psicologia, por sua vez, não deve se eximir dessa empreitada, que, como já apontado, trata-se de uma questão ética e política posta à profissão. As análises apresentadas podem auxiliar os profissionais da psicologia na compreensão dos fatores de riscos que os adolescentes estão expostos antes, durante e após a inserção em atividades vinculadas ao tráfico de drogas. A Figura 1 sumariza os achados desta investigação e ilustra os elementos centrais debatidos ao longo do artigo. 


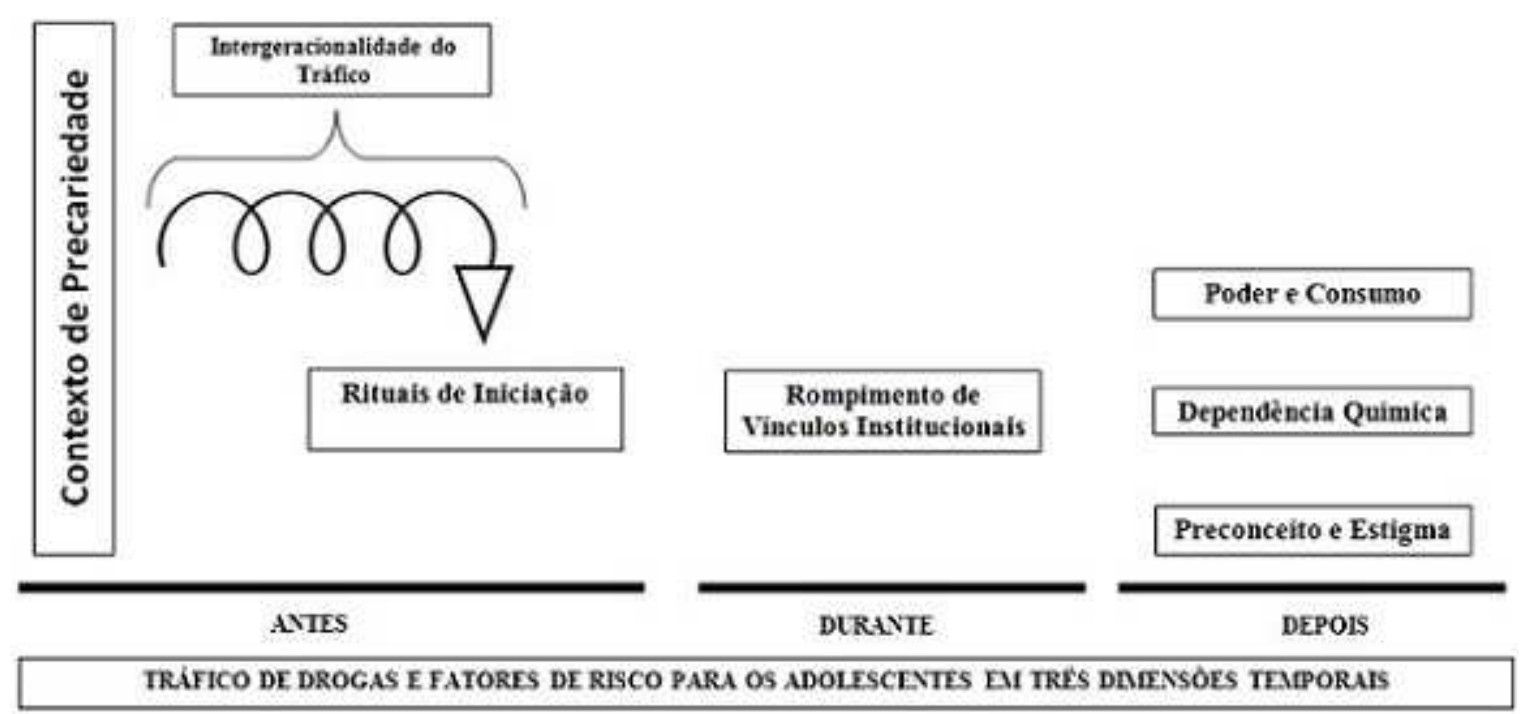

Figura 1 - Fatores de risco para adolescentes com envolvimento no tráfico de drogas.

\section{Considerações Finais}

Esta investigação revelou os fatores de risco presentes no contexto de adolescentes com histórico de envolvimento no tráfico de drogas. A pesquisa evidenciou o contexto de vida conturbado dos participantes antes da inserção em atividades vinculadas ao tráfico, mas também chamou a atenção para os fatores de risco que apareceram durante e após o início da comercialização de substâncias psicoativas. Por intermédio desta investigação, pode-se afirmar que as práticas dos profissionais da psicologia com adolescentes envolvidos no tráfico de drogas devem considerar os múltiplos fatores de risco que estão atrelados ao envolvimento deste grupo no tráfico de drogas. Certamente existem outros fatores de risco que não compareceram ao longo deste manuscrito. O debate ficou circunscrito aos temas que emergiram nas entrevistas de um pequeno grupo de adolescentes, o que explica parte das limitações deste estudo, dada a amostragem. Investigações de natureza quantitativa, que recorram à inserção ecológica e com recortes longitudinais certamente trarão à tona elementos que não foram explorados neste momento.

Além destes modelos de pesquisa sugeridos, como indicações para pesquisas futuras, recomenda-se a construção de modelos de intervenção psicológica baseados em evidências, tanto para a clínica quanto para os contextos institucionais, voltados para o atendimento de adolescentes com envolvimento em atos infracionais e, mais especificamente, no tráfico de drogas. Além disso, cabe destacar a necessidade da inclusão deste tópico nos cursos de formação inicial em psicologia, seja por meio de disciplinas ou por meio de atividades de formação complementar. 


\section{Referências}

Azevedo, C. R. S., Amorim, T. R. S., \& Alberto, M. F. P. (2017). Adolescência e ato infracional: Violência institucional e subjetividade em foco. Psicologia: Ciência e Profissão, 37(3), 579-594. doi:10.1590/1982-3703003312016

Bardin, L. (2011). Análise de conteúdo. São Paulo: Edições 70.

Bazon, M. R., Silva, J. L., \& Ferrari, R. M. (2013). Trajetórias escolares de adolescentes em conflito com a lei. Educação em Revista, 29(2), 175-199. doi:10.1590/S010246982013000200008

Brasil (1990). Lei n. 8.069, de 13 de julho de 1990. Dispõe sobre o Estatuto da Criança e do Adolescente e dá outras providências. Brasília, DF: Presidência da República. Recuperado de http://www.planalto.gov.br/ccivil_03/leis/18069.htm

Brasil (2012). Lei n. 12.594, de 18 de Janeiro de 2012. Institui o Sistema Nacional de Atendimento Socioeducativo (Sinase), regulamenta a execução das medidas socioeducativas destinadas a adolescente que pratique ato infracional. Brasília, DF: $\begin{array}{llll}\text { Presidência da } & \text { República. } & \text { Recuperado }\end{array}$ http://www.planalto.gov.br/ccivil_03/_Ato2011-2014/2012/Lei/L12594.htm

Cairus, R., \& Conceicao, M. I. G. (2010). Adolescentes na corda bamba: Aspectos psicossociais na relação com a lei. Revista Psicologia Política, 10(20), 275- 292. Recuperado de http://pepsic.bvsalud.org/scielo.php?script=sci_arttext\&pid=S1519549X2010000200007

Coelho, J. B., Pessoa, A. S. G., \& Bottrell, D. (2017). Perceptions of young offenders about the police: A qualitative study conducted in Brazil. Pesquisas e Práticas Psicossociais, 12(4), 1-17. Recuperado de http://www.seer.ufsj.edu.br/index.php/revista_ppp/article/view/2459

Conselho Federal de Psicologia. (2012a). Referências técnicas para atuação do em Medidas socioeducativas em Meio Aberto. Brasília, DF: Conselho Federal de Psicologia.

Conselho Federal de Psicologia. (2012b). Referências técnicas para atuação de psicólogos no âmbito das medidas socioeducativas em unidades de internação. Brasília, DF: Conselho Federal de Psicologia.

Costa, A. P. M., \& Goldani, J. M. (2015). A influência do contexto familiar nas decisões judiciais a respeito de atos infracionais de adolescentes: $O$ intervencionismo familiar ainda se faz presente? Textos \& Contextos, 14(1), 87-103. doi:10.15448/16779509.2015.1.20726 
Crochik, J. L., Casco, R., Ceron, M., \& Catanzaro, F. O. (2009). Relações entre preconceito, ideologia e atitudes frente à educação inclusiva. Estudos de Psicologia, 26(2), 123 132. doi:10.1590/S0103-166X2009000200001

Guitart, M. E. (2011). The consumer capitalist society and its effects on identity: A macro cultural approach. Revista Psicologia Política, 11(21), 159-170. Recuperado de http://pepsic.bvsalud.org/scielo.php?script=sci_abstract\&pid=S1519549X2011000100012\&lng=pt\&nrm=iso\&tlng=en

Kessler, G. (2010). Trabalho, privação, delito e experiência portenha [Work, hardship, crime and experience in Buenos Aires]. Tempo Social, 22(2), 79-99. Recuperado de http://www.revistas.usp.br/ts/issue/view/1003

Gomes, I. D., \& Colaço, V. F. R. (2016). Perigo, Aventura e Esperança: Discurso sobre risco em adolescentes autores de atos infracionais. Revista de Direitos e Garantias Fundamentais, 17(2), 353-382. doi:10.18759/rdgf.v17i2.813

Marques, A. C. S., \& Rocha, S. M. (2010). Representações fílmicas de uma instituição policial violenta: Resquícios da ditadura militar em Tropa de Elite. Revista FAMECOS, 17(2), 49-58. doi:10.15448/1980-3729.2010.2.7542

Mondini, C. E. C. M. (2011). Resiliência e medidas socioeducativas: Síntese dialética de múltiplas determinações (Dissertação de Mestrado). Universidade Federal de Mato Grosso do Sul, Corumbá, Brasil. Recuperado de https://ppgecpan.ufms.br/claudiaelizabete-da-costa-moraes-mondini-resiliencia-e-medidas-socioeducativas-sintesedialetica-de-multiplas-determinacoes/

Morais, N. A., Raffaelli, M., \& Koller, S. H. (2012). Adolescentes em situação de vulnerabilidade social e o continuum risco-proteção. Avances en Psicologia Latinoamericana, 30(1), 118-136. Recuperado de https://psycnet.apa.org/record/201336830-009

Nardi, F. L., \& Dell'Aglio, D. D. (2014). Trajetória de adolescentes em conflito com a lei após cumprimento de medida socioeducativa em meio fechado. Psico, 45(4), 541-550. Recuperado de https://dialnet.unirioja.es/descarga/articulo/6678126.pdf

Oliveira, A. M., \& Tomazetti, E. M. (2012). Quando a sociedade de consumidores vai à escola: Um ensaio sobre a condição juvenil no Ensino Médio. Educar em Revista, 44, 181-200. doi:10.1590/S0104-40602012000200012

Padovani, A. S., \& Ristum, M. (2013). A escola como caminho socioeducativo para adolescentes privados de liberdade. Educação e Pesquisa, 39(4), 969-984. doi:10.1590/S1517-97022013005000012 
Paiva, I. L., Souza, C., \& Rodrigues, D. B. (2014). Justiça juvenil: Teoria e prática no sistema socioeducativo. Natal: Editora da UFRN.

Pessoa, A. S. G. (2015). Trajetórias negligenciadas: Processos de resiliência em adolescentes com histórico de envolvimento no tráfico de drogas (Tese de Doutorado). Universidade Estadual Paulista, Presidente Prudente, São Paulo, Brasil. Recuperado de https://repositorio.unesp.br/handle/11449/135963

Pessoa, A. S. G., \& Coimbra, R. M. (2016). O traficante não vai à escola: Processos de escolarização de adolescentes com envolvimento no tráfico de drogas. Educação em Questão, 54(42), 190-217. doi:10.21680/1981-1802.2016v54n42ID10958

Pessoa, A. S. G., Coimbra, R. M., Koller, S. H., \& Ungar, M. (2018). Resiliência Oculta na Vida de Adolescentes com Envolvimento no Tráfico de Drogas. Psicologia: Teoria e Pesquisa, 34, e34426. doi:10.1590/0102.3772e34426

Pessoa, A. S. G., Coimbra, R. M., Noltemeyer, A., \& Bottrell, D. (2017). The applicability of hidden resilience in the lives of adolescents involved in drug trafficking. In D. D. Dell'Aglio \& S. H. Koller (Org.). Vulnerable Children and Youth in Brazil (pp. 247260). New York: Springer.

Predebon, J., \& Giongo, C. (2015). A família com filhos adolescentes em conflito com a lei: Contribuições de pesquisas brasileiras. Pensando familias, 19(1), 88-104. Recuperado de http://pepsic.bvsalud.org/scielo.php?script=sci_arttext\&pid=S1679494X2015000100008

Rocha, A. P. (2013). Proibicionismo e a criminalização de adolescentes pobres por tráfico de drogas. Serviço Social e Sociedade, (115), 561-580. doi:10.1590/S010166282013000300009.

Rodrigues, L. S., \& Chalhub, A. A. (2014). Contextos familiares violentos: Da vivência de filho à experiência de pai. Pensandofamílias, 18(2), 77-92. Recuperado de http://pepsic.bvsalud.org/scielo.php?script=sci_arttext\&pid=S1679494X2014000200007

Saewyc, E. M., Miller, B. B., Rivers, R., Matthews, J., Hilario, C., \& Hirakata, P. (2013). Competing discourses about youth sexual exploitation in Canadian news media. The Canadian Journal of Human Sexuality, 22(2), 95-105. doi:10.3138/cjhs.2013.2041

Sawaia, B. B. (2014). Transformação social: Uma questão para a psicologia social? Psicologia e Sociedade, 26(n. esp. 2), 17-25. doi:10.1590/S0102-71822014000600002

Silva, I. R. O., \& Salles, L. M. F. (2011). Adolescente em liberdade assistida e a escola. Estudos de Psicologia, 28(3), 353-362. doi:10.1590/S0103-166X2011000300007 
Ungar, M. (2004). The peer pressure myth. Relational Child and Youth Care Practice, 17(1), 11-17. Recuperado de https://www.cyc-net.org/profession/readarounds/ra-ungar.html

Ungar, M., Clark, S. E., Kwong, W., Makhnach, A., \& Cameron, C. A. (2005). Studying resilience across cultures. Journal of Ethnic \& Cultural Diversity in Social Work, 14(3-4), 1-19. doi:10.1300/J051v14n03_01

Ungar, M, Brown, M., Liebenberg, L., Othman, R., Kwong, W. M., Armstrong M., \& Gilgun, J. (2007). Unique pathways to resilience across cultures. Adolescence, 42(166), 287310. Recuperado

de https://go.gale.com/ps/anonymous?id=GALE\%7CA167585396\&sid=googleScholar\& $\mathrm{v}=2.1 \& \mathrm{it}=\mathrm{r} \&$ linkaccess $=\mathrm{abs} \& \mathrm{issn}=00018449 \& \mathrm{p}=\mathrm{AONE} \& \mathrm{sw}=\mathrm{w}$

Vicentin, M. C. G., \& Rosa, M. D. (2010). Os intratáveis: O adolescente, o ato e o imaginário social. Revista Psicologia Política, 10(19), 107-124. Recuperado de http://pepsic.bvsalud.org/scielo.php?script=sci_arttext\&pid=S1519549X2010000100010

Zappe, J. G., \& Dell'Aglio, D. D. (2016). Adolescência em diferentes contextos de desenvolvimento: Risco e proteção em uma perspectiva longitudinal. Psico, 47(2), 99110. doi:10.15448/1980-8623.2016.2.21494

\section{Endereço para correspondência}

\section{Alex Sandro Gomes Pessoa}

Universidade Federal de São Carlos

Departamento de Psicologia e Programa de Pós-Graduação em Psicologia

Rodovia Washington Luiz, km 235, Caixa Postal: 676, São Carlos - SP, Brasil. CEP 13565-905

Endereço eletrônico: alexpessoa@ufscar.br

\section{Renata Maria Coimbra}

Universidade Estadual Paulista Júlio de Mesquita Filho

Departamento de Educação

Rua Roberto Simonsen, 305, Centro Educacional, Presidente Prudente - SP, Brasil. CEP 19060-900

Endereço eletrônico: coimbralibor@uol.com.br

Recebido em: 03/09/2019

Reformulado em: 27/11/2019

Aceito em: 08/02/2020 


\section{Notas}

* Psicólogo (UNOESTE), Licenciado em Educação Física, Mestre, Doutor em Educação pela Universidade Estadual Paulista (UNESP) e Pós-doutorado em Psicologia (UFRGS).

** Psicóloga (PUC-Campinas), Mestrado em Psicologia Escolar e do Desenvolvimento Humano (USP). Doutorado realizado no Programa de Psicologia Escolar e do Desenvolvimento Humano (USP). Já realizou três Pós-doutorados.

Financiamento: Projeto de pesquisa financiado pela Fundação de Amparo à Pesquisa do Estado de São Paulo FAPESP (Proc. n 2012/07418-8 e Proc. nº 2012/22287-7).

Este artigo de revista Estudos e Pesquisas em Psicologia é licenciado sob uma Licença Creative Commons Atribuição-Não Comercial 3.0 Não Adaptada. 